\title{
CTEV WITH MEGA URINARY BLADDER: A CASE REPORT
}

KEY WORDS: CTEV-

Congenital Talipes Equino Varus.

\section{Priyanka \\ Dhiman*}

Suman Yadav

Balchander

Daisy Dwivedi

\section{Amit Verma}

Medical Officer, Anatomy, DRPGMC KANGRA (H.P.). *Corresponding Author

Principal (Professor Anatomy) Dr Radhakrishnan Govt Medical College, Hamirpur (H.P.).

Professor Pathology,DRPGMC Kangra (H.P.).

Assistant Professor Anatomy, Pt Jawahar Lal Nehru Govt Medical College Chamba (H.P.).

Senior Resident, Orthopedics, DRPGMC Kangra (H.P.).

Congenital talipes equino varus (CTEV), also known as congenital club foot is one of the common developmental deformities occurring at ankle, subtalar and metatarsal joints. Three elements comprise this deformity- equinus, inversion of foot and adduction of the forefoot relative to the hind-foot and equinus. The incidence of the deformity is 1 per 1000 live births. $20 \%$ of cases are associated with distal arthrogryposis, congenital myotonic dystrophy, myelomeningocele, amniotic band sequence and genetic syndromes such as trisomy 18 or chromosome 22 ql 1 deletion syndrome, in the remaining cases the deformity is isolated and the exact etiology is unknown. We are presenting a case of aborted male fetus of 20 weeks with congenital talipes equino varus in left foot with enlarged urinary bladder. The purpose of this report is to document the association of CTEV with enlarged urinary bladder.

\section{INTRODUCTION}

Congenital talipes equino varus (CTEV), also known as congenital club foot is one of the common congenital deformities occurring at ankle, subtalar and metatarsal joints. ${ }^{1}$ Three elements comprise this deformity- equinus, inversion of foot and adduction of the forefoot relative to the hind-foot and equinus. The incidence of this deformity is $l$ per 1000 live births. ${ }^{1}$ The deformity has four components: ankle equinus, hindfoot varus, forefoot adductus, and midfoot cavus. ${ }^{2}$

Congenital talipes equinovarus (CTEV), often known as 'clubfoot', is a common but little studied developmental disorder of the lower limb. It is defined as fixation of the foot in adduction, in supination and in varus, i.e. inclined inwards, axially rotated outwards and pointing downwards. The calcaneus, navicular and cuboid bones are medially rotated in relation to talus, and are held in adduction and inversion by ligaments and tendons. Although the foot is supinated, the front of the foot is pronated in relation to back of the foot, causing cavus. In addition, the first metatarsal is more plantar flexed. Congenital talipes equinovarus is termed 'syndromic' when it occurs in association with other features as part of a genetic syndrome, or it can occur in isolation in which case it may be termed 'idiopathic'. Syndromic talipes equinovarus arises in many neurological and neuromuscular disorders, for example spina bifida or spinal muscular atrophy, but the idiopathic form is by far the most common. The upper limb is normal in idiopathic CTEV. ${ }^{3}$

\section{OBSERVATION}

During routine fetal autopsy in pathology department in DRPGMC Kangra at Tanda (H.P.), received a male fetus of 20 weeks gestational period, with crown rump length is $19 \mathrm{~cm}$, with unilateral talipes equino varus in right foot, with enlarged urinary bladder. Rest of the organs was normal and found in their original position.

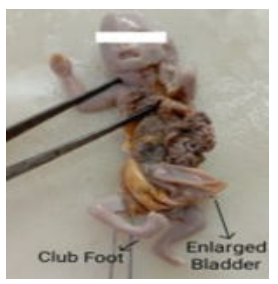

\section{DISCUSSION}

CTEV is one of the most common congenital birth defects with prevalence of 1 per 1000 live births. $20 \%$ of cases are associated with distal arthrogryposis, congenital myotonic dystrophy, myelomeningocele, amniotic band sequence and genetic syndromes such as trisomy 18 or chromosome $22 q 11$ deletion syndrome, while in the remaining cases the deformity is isolated and the exact etiologyis unknown.

Yong et al. analysed 21 studies that have examined the genetic variants related to idiopathic CTEV, reported positive association with Hox family genes, collagen family genes, Tbox family genes, apoptotic pathway genes, and muscle contractile family genes.

Singal $\mathrm{R}$ et al. reported a rare case of a newborn baby with an abdominal wall defect, together with multiple congenital abnormalities and diagnosed as gastroschisis. There were multiple defects seen as spinal deformity, imperforate anus, esophageal fistula, and lower limb deformity (congenital talipes equino varus) along with the webbing of neck. ${ }^{5}$

There is strong evidence for a genetic component to the aetiology of CTEV. Idelberger's (1939) twin study found concordance for ICTEV in 32\% of monozygotic twins in his series, compared to $2.9 \%$ concordance in dizygotic twins. ${ }^{3}$

Literature regarding the association of CTEV and Mega Bladder is far less available.

\section{CONCLUSION}

The purpose of this report is to document the association of CTEV with enlarged urinary bladder. Further studies are required to know the molecular basis of this association.

\section{REFERENCES}

1. Arif M, Inam M, Sattar A, Shabir M. Usefulness of Ponseti technique in management of congenital telipes equino-varus. J Pak Orthop Assoc. 2011 23:62-4.

2. Ponseti IV. Club foot management. 2000; 20:699-700.

3. Zosia Miedzybrodzka. Congenital talipes equinovarus (clubfoot): a disorder of the foot but not the hand.JAnat 2003 Jan;202(1):37-42

4. BCYong, FX Xun, LJ Zhao, HW Deng, HW Xu - Springer plus, 2016 - Springer. A systematic review of association studies of common variants associated with idiopathic congenital talipes equinovarus (ICTEV) in humans in the past 30 years. Springerplus (2016) 5:896.

5. Singal R, Garg LN, Singal RP, Gupta S, Shahi SR, Singal S, et al. Omphalocele and Gastroschisis Associated With Multiple Congenital Abnormalities. J Med Life. $2011 ; 4: 295-6$. 